\title{
Universidad para la liberación: la proyección social de la UCA
}

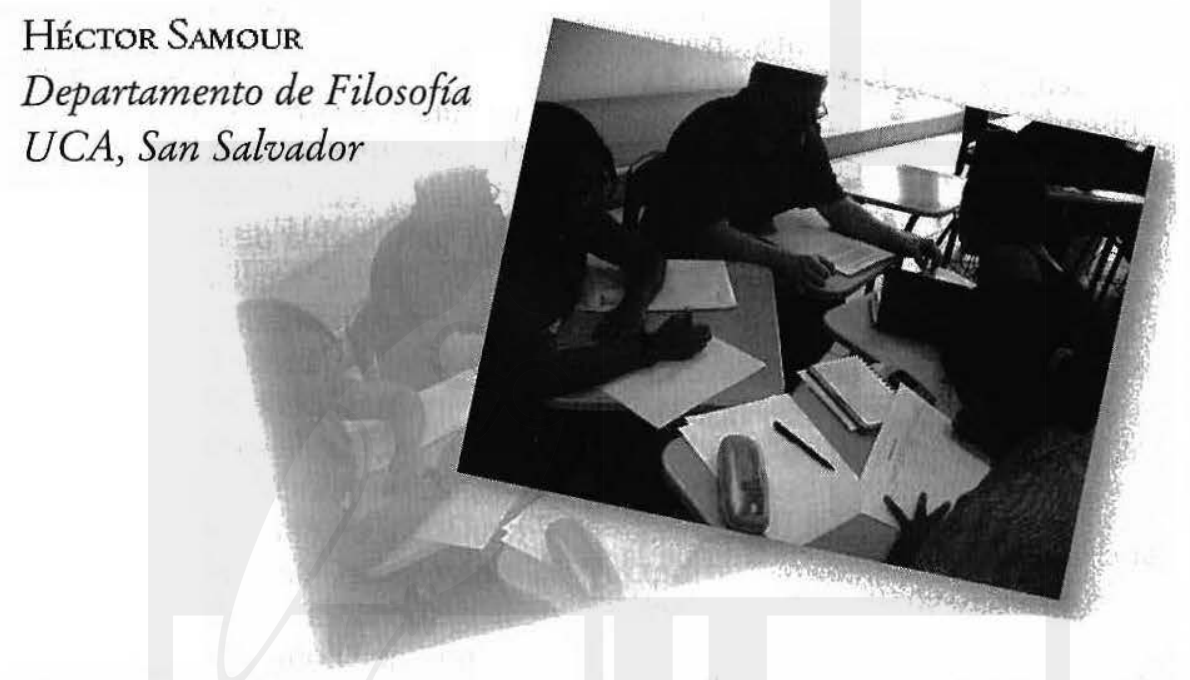

RESUMEN: En el siguiente ensayo se plantea que la finalidad última de la institución universitaria en un país con las estructuras socioeconómicas injustas de El Salvador debe ser la de contribuir universitariamente a la liberación de las mayorías empobrecidas. Una de las formas en que se concreta esa finalidad es a través de la proyección social, que no es asistencialismo, sino compromiso universitario con la sociedad y su liberación.

ABSTRACT: The following essay poses that, in a country with unfair social and economic structures like El Salvador, the university must contribute to the liberation of the impoverished majorities. One way to approach this aim is through the social projection, which is not charity, but the university's commitment with the society and its liberation. 


\section{Del desarrollismo a la liberación}

$\mathrm{E}$ discurso de la UCA en la firma del contrato con el BID, a cinco años de haber sido fundada, marca el inicio de la concepción de la proyección social de la universidad. En dicho discurso se afirmaba lo que la UCA entendía por su misión universitaria, enfatizando su carácter histórico: "Si la Universidad se entendiera como busca utópica de una verdad intemporal, podría pensarse que su misión fuera unívoca; pero si la Universidad se entiende como servicio al pueblo que le da su ser, entonces ha de entenderse como función estrictamente histórica. Su realización universitaria puede ser profundamente diversa en situaciones dispares. Lo que en cada caso determine su historicidad será la situación histórica del pueblo al que debe servir".

Se marcaba así una ruptura con la concepción de universidad que la UCA suscribió en sus tareas fundacionales en 1965, cuando enmarcaba su servicio en la línea del desarrollismo imperante en la época. Ahora se apuntaba a la superación de dicho desarrollismo y el paso al paradigma de liberación: "el trabajo por el desarrollo, que lucha por la elevación impostergable de los más necesitados, lleva en sí mismo la dinámica de su propia superación... La tarea del desarrollo, que ha servido de ideal a los mejores hombres de nuestro continente, impulsa hoy a un ideal superior que, incorporando el desarrollo, va más allá". ${ }^{2}$
Ya no se trataba de concebir el desarrollo de un país como mero crecimiento económico para conducirlo hacia lo que hoy son los países que se estiman desarrollados y siguiendo los mismos caminos por los que avanzaron hasta su estado actual. El desarrollo que debía pretender la universidad pretendía ser integral y promover a todos los seres humanos $y$ a todo ser humano.

Para ello, la universidad, según el discurso, debería dedicarse al estudio de aquellas estructuras, que como tales, "condicionan para bien o para mal la vida de todos los ciudadanos. Debe analizarlas críticamente, debe contribuir universitariamente a la denuncia y destrucción de las injustas, debe crear modelos nuevos para que la sociedad y el estado puedan ponerlas en marcha". ${ }^{3}$ Vinculada a esta tarea fundamental, la universidad, según el discurso, debe despertar la conciencia de "los derechos del hombre centroamericano en el ámbito de la patria común y en el de la comunidad de las naciones". Y esto ha de hacerse, no con prédicas moralizantes, sino con estudios contundentes. "A través de sus tres facultades - se afirmabadeberá promover aquel desarrollo educativo, económico e industrial, que dé posibilidades reales de satisfacer necesidades reales" ${ }^{4}$

Según este documento, el concepto que culmina el desarrollo integral, es el concepto de libertad. 
"No aquella libertad negativa del "dejar hacer", sino aquella plenitud de libertad positiva sin la que la persona humana no alcanza a ser lo que es. "Una libertad que en la situación actual de nuestros pueblos debe entenderse inicialmente como liberación, es decir, como aquel proceso que haga desaparecer todo lo que haya de opresivo en lo biológico, en lo social y en lo económi$\mathrm{Co}$, en lo político y en lo cultural". ${ }^{5}$

\section{Universidad para el cambio social}

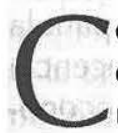

on ocasión de los diez años de su fundación, en 1975, en un discurso del rector de la época ${ }^{6}$ se aclaraba más ampliamente el rol social de la universidad, en una sociedad dividida y conflictiva como la de El Salvador. En este contexto, según Román Mayorga Quiróz, limitar la acción universitaria al mero propósito de brindar una carrera profesional al núcleo, porcentualmente ínfimo de la población, que tiene acceso cultural y económico a tal posibilidad, sería cortar de tajo la realización de las potencialidades de servicio que la universidad puede y debe prestar al pueblo salvadoreño. "Privilegiar, entonces, en la cumbre universitaria de la pirámide, al que ya es privilegiado, con - exclusivamente- los conocimientos técnicos que puede emplear para solo aumentar su privilegio, es hacerle el juego a las estructuras que niegan una vida digna a la vasta mayoría de la población, que no tiene, ni tendrá en mucho tiempo, la oportunidad de recibir una educación equivalente ${ }^{\prime \prime} .^{7}$ Esto no significa negar la imprescindible necesidad de cuadros, universitariamente formados, para un proceso social que conduzca a una sociedad muy humana y solidaria, sino que la docencia universitaria "no debe meramente ajustarse a las demandas de educación neutra, atemporal y ahistórica, que le hace la sociedad, tal y como ahora se encuentra estructurada. Ajustarse estrechamente a tales demandas... ha sido uno de los principales errores históricos de la universidad latinoamericana" ${ }^{8}$

Según Román Mayorga, el otro gran error histórico de la universidad latinoamericana había sido permitir una confusión de planos, en cuanto a su propio rol, en el necesario proceso de transformación social: "No caer en la cuenta de los límites de su posibilidad; mal entender su legítima dimensión política, dejándose enfrascar en luchas partidarias por el poder... subestimar el valor de la acción universitaria que se ubica en un plano superestructural de la conciencia; volverse coyunturalista; dejarse instrumentalizar por partidos políticos, gobiernos, iglesias, gremios, oligarquías y otros grupos que posiblemente desearían servirse de la entidad universitaria, para fines distintos a los que son propios de su servicio... La única justificación mo- 
ral de una universidad de inspiración cristiana, es el servicio al pueblo, y su única parcialidad admisible es el servicio a todos desde el favorecimiento a las mayorías desposeídas". ${ }^{9}$

Frente a estos dos grandes errores históricos -el camino profesionista de la seudo-neutralidad científica y el de la instrumentalización partidaria y parcializante del rol social universitario-se proponía el camino que la UCA debería seguir: "el de la solidez científica comprometida con un pueblo en su realidad histórica concreta" ${ }^{10}$ Según esto, era necesario, en primer lugar, que la política de investigaciones de la universidad se orientara a fortalecer la base de ideas y proyectos, globales y sectoriales, que se necesiten para la transformación social. $Y$ en segundo lugar, que se buscara crear una base humana de profesionales, suficientemente amplia y diversificada para realizar un "proceso social liberador".
Decía el texto citado: "... la base humana de dirigentes de la transformación social no saldrá de la lucha empírica por el poder, cuando del entramado de una verdadera universidad, en continua interacción con las realidades sociales... La política de docencia en la universidad debe, por tanto, orientarse a fortalecer esa base o infraestructura imprescindible para la transformación social... la docencia debe realizarse con pleno reconocimiento de que los profesionales que se necesitan, deben no sólo poseer un alto grado de competencia técnica en su respectiva disciplina, sino también un profundo espíritu de solidaridad y justicia hacia el pueblo oprimido. En este sentido, no importa tanto el número de graduados universitarios que logremos, siempre pequeño porcentualmente, cuanto su calidad y el tipo de motivaciones de que auténticamente se encuentren animados" ${ }^{11}$

\section{Universidad como conciencia crítica y creadora de la realidad}

En esa misma época, Ignacio Ellacuría, refiriéndose a las posibilidades de una universidad distinta, en la línea de una universidad inmersa en una conciencia liberadora, afirmaba en un artículo ${ }^{12}$ que "el sentido último de una universidad y lo que es en su realidad total debe mensurarse desde el criterio de su incidencia en la realidad histórica, en la que se da y a la que sirve. Debe men- surarse, por tanto, desde un criterio político". ${ }^{13}$ Esto lleva a preguntarse explícitamente por la dimensión política de la universidad, "porque esta dimensión es un hecho innegable y un hecho de grandísima importancia para la orientación misma de la universidad. El carácter distinto de la universidad no estará, entonces, en no cumplir con su misión política sino en cumplirla de otra manera" ${ }^{14}$ 
Frente a las dos formas inadecuadas y falsificadoras de politización de la universidad -la de contribuir a robustecer el sistema dominante respondiendo positivamente a sus demandas, o la enfrentarse con el sistema, según el modo de hacerlo de los partidos políticos de oposición o de las organizaciones populares-, Ellacuría proponía lo que debe ser la misión política de la universidad o mejor dicho, "el modo universitario de realizar la tarea de liberación".

Se trata, en primer lugar, de parcializar la universidad, o mejor dicho de optar por una de las parcializaciones ineludibles, en el contexto de una sociedad dividida $y$ contrapuesta. La universidad no debe tener como horizonte último de su actividad los intereses subjetivos de sus miembros, sino "los intereses objetivos, científicamente procesados, de las mayorías oprimidas". ${ }^{15}$

En segundo lugar, se debe hacer de la cultura el campo propio de la actividad universitaria, entendida "como acción cultivadora y transformadora de la realidad". La cultura creada por la universidad tiene así una esencial sentido práxico, "por cuanto proviene de una necesidad de acción y debe llevar a una acción transformadora del propio sujeto $y$ de su contorno natural e histórico". ${ }^{16}$ Lo que se debe buscar es la configuración de "una conciencia colectiva debidamente procesada y convenientemente operativizada" en función de los cambios necesarios para lograr la liberación, pero sin caer en un idealismo de la historia, que supone que los cambios se darán en el puro ámbito del saber y de la conciencia con independencia de las estructuras sociales y de la praxis colectiva.

En la búsqueda de esta cultura crítica y liberadora, la universidad, según Ellacuría, "debe intentar dar resonancia al sentir profundo del pueblo, al sentir de sus necesidades, de sus intereses, de sus sentimientos, de sus apetencias, de sus valores. Cultura nacional no es, entonces, folklore nacional, aunque el folklore puede que exprese algunos aspectos importantes del ser popular". ${ }^{17}$ Se debe evitar, por tanto, una consideración estetizante de la cultura nacional que puede llevar al narcisismo y la quietud, "cuando lo que se necesita es operatividad para la construcción de un hombre nuevo en una tierra nueva. La cultura debe ser vigilancia despierta, tensión hacia el futuro, transformación". ${ }^{18}$ Lo que está en juego en la cultura es la realidad histórica de! país, "la realidad dinámica de un nación que se está haciendo y a cuyo hacer contribuyen una multitud de fuerzas $y$ factores".

Pero la cultura debe ir también a la constitución de nuevos valores, lo cual supone desenmascarar los presentes, en muchos de los cuales se legitima la dominación. Desde esta perspectiva, la cultura se convierte en crítica ideológica o lucha ideológica, lo cual supone sacudimiento y ruptura con la cultura dominante. 
Esta es la manera, según Ellacuría, como la universidad puede convertirse en "conciencia crítica y creadora" de la realidad nacional. Se debe construir una cultura liberadora - decía Ellacuría- para no dejar "la historia de un pueblo en las manos exclusivas de los cultivadores políticos del pueblo, de los cultivadores que buscan el poder (supuestamente) para el pueblo, ya no digamos de cultivadores de otro corte político". La cultura de la universidad debe ser "una cultura que rompa todo vínculo de dominación, una cultura que avance hacia una liberación siempre mayor, pero una cultura realmente vivida en cada paso del proceso". ${ }^{19}$

El método fundamental de la acción universitaria en esta tarea es, según Ellacuría, el de la "palabra eficaz", un término que resume en esa época lo que debería ser el impacto de la proyección social de la universidad: "Por palabra se entiende aquí la comunicación recibida $y$ comprendida de la cultura reelaborada por la universidad... Cultura y palabra son así inseparables; la cultura de la universidad no puede quedarse dentro de ella sino que es, desde un principio, cultivo, acción 0 , al menos, principio de acción" ${ }^{20}$

Esta palabra debe caracterizarse por ser "poderosa", en el sentido de su racionalidad $y$ cientificidad, $y$ debe mostrar su eficacia en diversos órdenes: en el orden del análisis de la realidad, del juicio que esa realidad merece y de los medios para transformarla; en el orden del en- juiciamiento ético tanto de orientaciones generales como de determinadas acciones públicas. Lo que se pretende es que esa palabra se haga historia, porque es la única manera de que sea eficaz: "... si se va logrando una cultura... y se va logrando comunicar esa cultura a la realidad y a la conciencia nacional, la eficacia será innegable. Podrá ser lenta porque la historia tiene su propio paso, que no es el de las vidas individuales, pero hará historia. Y lo que no llega a convertirse en historia, más en concreto, en estruclura histórica, corre el peligro de ser flor de un día para los demás, aunque para uno mismo cobre singular relieve" ${ }^{21}$

Se trata, por tanto, de propiciar una transformación estructural de la sociedad. Ellacuría recalca que la actividad universitaria no busca primariamente la transformación de las personas, sino de las estructuras. No es que ambos objetivos -la referencia a las personas y la referencia a las estructuras- sean contradictorios o que se excluyan entre sí, pero el poner el acento en una de ellas cambia notoriamente la dirección del trabajo universitario. La universidad debe focalizar su aporte específico sobre el problema estructural. Aquí está implícito un supuesto filosófico en el planteamiento ellacuriano, de raíz zubiriana: la única manera de alcanzar la realidad y de atinar con su esencia es alcanzar su estructura. De lo contrario, "no se encontrará la realidad". "La realidad en gene- 
ral es estructural $y$ la realidad social es especialmente estructural... No hay otra posibilidad de alcanzar una dimensión como es la realidad nacional, que la de ir en busca de sus estructuras; de lo contrario, la realidad nacional perseguida a través de sus partes o de sus individuos, es evidentemente inalcanzable, $y$ aunque fuera alcanzable, resultaría inoperable". ${ }^{22}$

Una primera consecuencia de este plantearniento es que el objetivo principal o primario de la universidad no debe ser la formación de profesionales. "La única justificación del enfoque de la universidad hacia la formación de profesionales como dirección primaria de su actividad, sería la de entender que solo con profesionales bien formados podría llegarse a la transformación estructural del país; con lo cual se estaría reafirmando la prioridad de la transformación estructural". Pero como en el actual sistema no es posible realizar esto con una universidad orientada primariamente a la profesionalización, ni siquiera se puede dar esa razón como justificación válida.

Una segunda consecuencia es que tanto la investigación como la proyección de la universidad en la sociedad "deben quedar orientadas por este objetivo de lo estructural y de lo estructural en trance de transformación. Una transformación que no se reduce, evidentemente, a transformación de conciencia, aunque también la conciencia colectiva participe de un cierto carácter estructural, sino que debe llegar a la transformación de las estructuras de toda índole hasta culminar en la transformación de las estructuras socio-económicas y políticas". ${ }^{23}$

Este acento en lo estructural puede parecer que soslaya lo personal, o que minimiza su importancia en la labor universitaria, pero lo que hay que entender, según Ellacuría, es que "la salvación (realización) de lo personal no puede concebirse realísticamente al margen de lo estructural. La pregunta entonces, es qué estructuración de la sociedad permite el desarrollo pleno y libre de persona humana y qué acción personal en la transformación de las estructuras debe ser la de quienes en ella participan". En definitiva, se trata de que la universidad, con su ciencia, su técnica, su profesionalización y su composición misma, se realice participando en una "praxis histórica de transformación de estructuras" (término que sería el equivalente a lo que en su filosofía de la historia Ellacuría denomina 'praxis histórica de liberación'), y que en esta acción y objetivación históricas posibilite la recuperación del ámbito real para una auténtica entrega y realización personal. ${ }^{24}$

Estos planteamientos fueron asumidos en el documento de la Junta de Directores, Funciones fundamentales de la universidad y su operativización, de mayo de 1979. Aquí la UCA reitera su identidad como una universidad para el cambio social, que "debe buscar, ofrecer $y$ apoyar universitariamen- 
te los procesos que propicien una convivencia más justa, libre y solidaria en El Salvador y Centroaméri$\mathrm{ca}^{\prime \prime}$. Se insiste que esto supone una politización de la universidad como un todo, que no implica en modo alguno un abandono de lo universitario a favor de lo político partidarista. "No se pretende el cultivo del saber por el saber o la formación de profesionales en $y$ por sí misma sino el cultivo de la realidad nacional y la formación de aquellos que pueden contribuir a que esa realidad sea mejor, más justa y racional... Se trata de construir un saber consciente sobre el pueblo, su realidad $y$ sus problemas, que sea al mismo tiempo un saber útil para que ese mismo pueblo pueda caminar hacia su liberación. La UCA debe descubrir las causas y condiciones sociales que han producido y mantienen la actual situación de opresión del pueblo salvadoreño $y$, creativamente, debe encontrar y ofrecer ideas, modelos teóricos y técnicas, cuya realización concreta pueda propiciar la existencia de estructuras más humanas $y$ humanizadoras. A otras fuerzas sociales tocará, sin embargo, esa realización histórica concreta, ligada a conflictos de intereses y relaciones de poder". ${ }^{25}$

Se destaca, además, el carácter estructural de la universidad, como una unidad en la diversidad de sus integrantes, instancias, actividades y disciplinas, donde cada uno tiene su propia especificidad y sus propios objetivos. "Obviamente no todas y cada una de las disciplinas, no todas y cada una de las actividades universitarias, pueden referirse del mismo modo y con la misma inmediatez al objetivo general y último" de contribuir a la liberación. Es la universidad como un todo, a través de la pluralidad de funciones de las partes que la constituyen, la que se pone al servicio de la tarea liberadora. Hay así una dialéctica entre partes $y$ todo: las partes son necesarias para que haya universidad y para que ésta proceda universitariamente; son partes sin las que el todo no puede ser lo que debe ser. Pero, a su vez, es el todo quien estructura unitariamente las partes y quien les da su realidad y su sentido último. ${ }^{26}$

Por tanto, se afirma que la estructura misma de la universidad no solo permite la diversidad y el pluralismo, sino que los exige. Es un pluralismo que permite incluso la colaboración de quienes se ciñen a cumplir con sus tareas específicas, aunque no estén comprometidos con los objetivos últimos de la universidad. Es un pluralismo que permite la libertad académica que "discute críticamente la manera de alcanzar los objetivos generales de la universidad". ${ }^{27}$

La proyección social de la universidad queda definida aquí como "una función, a través de la cual se pretende conseguir la finalidad última de la universidad; mediante ella se busca directamente la incidencia real del quehacer universitario en el cambio social. En un sentido más restringido, supone un conjunto de 
actividades peculiares, que inciden en forma directa sobre la sociedad $y$ pretenden positiva $y$. exclusivamente ese cambio". A diferencia de la docencia y de la investigación, la proyección social "procura poner la universidad como totalidad, aunque a través de sus partes, en relación directa con las fuerzas y procesos sociales en la línea del deseado cambio social. Su destinatario inmediato es la sociedad, sea en su conjunto, sea en algunos de sus sectores más determinantes". ${ }^{28}$

Se afirma, además, que la determinación del modelo concreto de sociedad que la universidad quiere propiciar es algo que no se puede determinar a priori. La investigación y la proyección social deberán ir determinando el marco general posible de transformaciones para la sociedad salvadoreña a largo plazo, y se deberán ir adelantando determinaciones o salidas de solución más concretas $y$ viables, de corto o mediano plazo, a los problemas sociales que afectan a las mayorías.

En esta línea, la UCA deberá apoyar aquellos procesos que, en su finalidad y sus métodos, sean más conformes con su ideal utópico de sociedad y con lo que es su inspiración cristiana. La UCA deberá estar siempre atenta a la dirección real del proceso de cambio y a las fuerzas sociales que lo promueven en la dirección más correcta. "Deberá, por tanto, concretar sus aspiraciones ideales a las posibilidades reales del país en cada uno de sus momentos históricos... Esto implica un sano realismo político manteniendo la tensión entre lo que debería ser y lo que puede alcanzarse en cada momento". El documento aclara que esto no supone una acomodación sumisa al poder, ya que la universidad, al no estar o no participar en la esfera del poder político, le permite no identificarse nunca con él, manteniendo así una distancia crítica, que no excluye una cierta colaboración, siempre y cuando sea en beneficio de las mayorías. ${ }^{29}$

En el documento se resalta también la importancia de motivar y orientar periódicamente al personal de la UCA y sus actitudes hacia la importancia de la proyección social. Aclararle en qué consiste, buscar los medios adecuados de realizarla, planificarla convenientemente, y unificarla con el resto de la actividad universitaria. Se considera un error que cada uno se lance de por sí a actividades de proyección social o que existan unidades especializadas de proyección, desvinculadas del resto de las actividades universitarias. Según el documento, es necesario elaborar un proyecto general de proyección social, para que dicha proyección responda a lo que es la universidad como un todo, sobre todo si se trata de la proyección social de la UCA en cuanto tal y no de la promovida por un individuo o un grupo a título personal o grupal.

Se propone, adicionalmente, determinar las diversas áreas de trabajo de la UCA para jerarquizarlas en relación con la proyección social. Un criterio importante de 
jerarquización que se señala es el influjo social permanente (no coyuntural) de una determinada área. Además, se ve necesario desarrollar modos precisos para evaluar y medir el impacto real de la proyección social según la orientación requerida, y evitar autocomplacencias, en las que se supone de antemano, sin verificación ulterior, que lo que produce o hace la UCA es automáticamente proyección social con la dirección debida y deseada.

El documento concluye, después de resaltar la importancia de fortalecer los canales a través de los cuales el producto elaborado por la UCA "Ilegue a quien debe llegar y llegue del modo como debe llegar", que la idea maestra que debe dirigir la proyección social es la de "elaborar un producto racional, mediante la colaboración de toda la potencialidad de la universidad, que sea en sí mismo de gran virtualidad social, sea total o sectorial". Y en este sentido, antes de preocuparse por la "proyección" del producto hay que preocuparse por su "gran capacidad de transformación social, sea por el diagnóstico que presenta, o por las soluciones que propone, o por los valores que transmite". ${ }^{30}$

Se finaliza señalando que un tipo de universidad así concebida tiene un impacto social importante, porque puede ofrecer el ejemplo real de cómo una institución que no está basada en el motivo del lucro y de la ganancia, al modo de una empresa capitalista, que ni siquiera está fundada en la propiedad privada, puede ser plenamente eficiente. También porque muestra una voluntad de organizarse internamente en función del cambio social y de establecer entre sus miembros un tipo de relaciones que respondan al cambio social deseado. En esta línea se recomienda que, al nivel de relaciones internas, se fomenten la solidaridad, la justicia, la participación personal, el interés y el respeto por los individuos, con el fin de que se implemente todo aquello que mejor conduzca a la incidencia universitaria en la sociedad.

\section{Universidad y política}

"Universidad y política" es el título de un artículo de Ignacio Ellacuría que salió publicado en ECA en $1980^{31}$. Se relaciona por la temática con una ponencia de Ellacuría de 1976, titulada "Una universidad centroamericana para El Salvador". ${ }^{32}$ En ambos textos se pretende fundamentar filosóficamente la dimensión política de la universidad y dar pistas para resolver el problema de su politicidad.

Se parte de una afirmación sobre una idea que ya habíamos mencionado brevemente al principio: el intrínseco carácter político de la universidad se deriva de su esencial carácter histórico. La universidad es una realidad política por que es una realidad histórica. Esto signi- 
fica, por un lado, que no existe la universidad o una universidad que deba implantarse en todos los tiempos y en todos los lugares - punto importante, deslaca Ellacuría, para no trasladar mecánicamente modelos impuestos de universidad-; por otro, significa que la universidad está condicionada por lo que es la realidad en la que se da, $y$ que, por lo tanto, debe esforzarse en no ser arrastrada por lo que es su contexto histórico, buscando contra-condicionar o transformar dicho contexto desde su carácter de universidad. De aquí se desprende que no puede ni debe haber una universidad a-política. No debe haberla, "porque una universidad que no quisiera positivamente $y$ desde sí misma ser política, estaría forzosamente politizada, pues tendría una u otra relación con el poder del Estado y tendría uno $u$ otro influjo sobre el conjunto de poderes que condicionan el ser de la sociedad; sería política a su pesar, esto es, irracional e indeliberadamente, lo cual sería la negación de su propia esencia". ${ }^{33}$

Por tanto, Ellacuría entiende por universidad política, ${ }^{34}$ en primer lugar, una universidad que debe pretender incidir sobre la reestructuración y conformación de la sociedad, de los poderes sociales $y$, mediatamente, de los poderes político-estatales. En segundo lugar, que no sea universidad y "además" tenga algunas actividades políticas, sino que toda su labor universitaria esté orientada $y$ animada por una clara intencionalidad política, que no distorsione la especificidad de la labor universitaria, pero sí la obligue a optar y a orientarse por una opción socio-política fundamental. En tercer lugar, que tenga un juicio $y$ una opción fundamentales sobre la realidad política como un todo y sobre la dirección que ha de dársele a esa realidad política. $Y$, finalmente, que permanentemente se pregunte por qué fuerzas de la sociedad está consciente $\mathrm{o}$ inconscientemente dirigida y a qué fuerzas está positivamente sirviendo o negativamente dejando de servir.

Desde estos presupuestos, Ellacuría afirma que, en nuestro contexto, la politicidad fundamental de la universidad se elabora al darle prioridad y rango directivo a la proyección social sobre la docencia $y$ la investigación, entendiendo aquí dicha proyección como "aquella que busca prioritariamente la radical transformación del desorden (institucional) establecido y la injusticia estructural". "S5 Según esto, la proyección social "no se confunde - afirma Ellacuría- ni con la extensión universitaria, que busca regalar migajas de cultura a grupos que no pueden acceder a la universidad ni tampoco se confunde con el servicio social, esto es, con el trabajo que alumnos y profesores pueden hacer supletoriamente en favor de determinados grupos sociales". ${ }^{36}$

Reitera que uno de los aportes importantes para realizar la proyección social es la elaboración de un diagnóstico científico y/o racional sobre la realidad histórica del país en su conjunto y sus partes, inclui- 
do el análisis y la crítica de la ideología oficial o de la forma en que ven y aprecian esa realidad los grupos sociales dominantes, así como la propuesta de modelos y valores nuevos. También, Ellacuría señala la importancia de producir "un saber crítico" (liberador), lo cual supone "una reflexión epistemológica sobre cualquier saber, pero también una reflexión ética, igualmente crítica, sobre todo saber y todo hacer" ${ }^{37}$

Con estos aportes fundamentales, se pretende que la universidad se constituya en "momento iluminador y propulsor, reflexivo y crítico" de los procesos que efectivamente favorezcan el cambio social, e incluso convertirse, cuando ello es posible, en un factor importante en la configuración del elemento subjetivo o ideológico de una praxis liberadora. ${ }^{38}$
Pero la proyección social no se reduce a esto; pretende, además, según Ellacuría, intervenir directamente en aquellos centros de decisión o de poder, que determinan cuestiones importantes en la marcha de la sociedad, con el fin de propiciar o posibilitar las transformaciones requeridas o proyectadas.

El objetivo último de la politización universitaria, concluye Ellacuría, está determinado "por las exigencias objetivas de las mayorías populares, exigencias deducibles tanto de su propia realidad objetiva en el contexto social como de su voluntad expresa manifestada" en sus luchas de emancipación. Esta opción preferencial por las mayorías oprimidas "se realiza configurando toda la labor universitaria desde las necesidades de las mayorías y liberando el mayor potencial posible para la proyección social formalmente tal". ${ }^{39}$

\section{Universidad, mayorías populares y liberación}

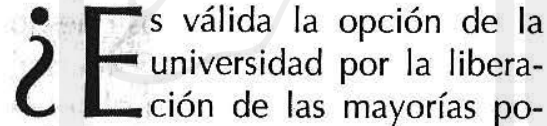
pulares? " Debe la universidad en cuanto universidad dedicarse formal y explícitamente a la defensa de los derechos humanos fundamentales de las mayorías populares o esa es solo una tarea que, en el mejor de los casos, debe ocuparla de un modo tangencial y derivado?". ${ }^{40} \mathrm{EI}$ artículo de Ellacuría, "Universidad, derechos humanos y mayorías po- pulares", de 1982, está orientado principalmente a dar respuestas a estas preguntas y a justificar teóricamente la opción fundamental de la universidad por la liberación de dichas mayorías. En otro artículo ${ }^{41}$, Ellacuría se había referido también a una justificación ética y a una justificación cristiana de la opción por las mayorías pobres; pero ahora concentra en la justificación teórica.

Ellacuría comienza con la afirmación de un supuesto epistemoló- 
gico polémico: "el lugar teórico por excelencia para enfocar los grandes problemas sociales, en orden a su interpretación correcta y su solución práctica, es, en general, el de las mayorías populares". ${ }^{42}$ La cuestión de la parcialidad en el conocimiento de lo real, es una cuestión epistemológica debatida en el ámbito de la filosofía de la ciencia, porque supuestamente estaría atentando contra las características de pureza, objetividad y neutralidad que deberían caracterizar el conocimiento científico de la realidad, según el paradigma del cogito cartesiano $y$ del método científico moderno. Sin embargo, la episternología contemporánea ha cuestionado definitivamente la orientación empirista y positivista y cada vez ha ido poniendo en claro el carácter histórico, situado y hermenéutico del conocimiento de la realidad, incluyendo el conocimiento producido por las ciencias físico-matemáticas.

Según esto, lo que afirma Ellacuría es que en sociedades divididas y contrapuestas, donde predomina la injusticia, "son las mayorías y su realidad objetiva el lugar adecuado para apreciar la verdad o la falsedad del sistema en cuestión; un sisterna social que mantiene por largo trecho de tiempo a la inmensa mayoría en una situación deshumanizada, queda refutado por esta misma deshumanización mayoritaria".43 De ahí la importancia que Ellacuría le da, en la producción de conocimiento, al momento opcional por el "lugar-que-da-verdad y que hace verdad", y que está vinculado a la postura ética que rechaza las situaciones de injusticia y de no-libertad que se dan en nuestra realidad histórica, y vinculado, también, a la valoración teórica-epistemológica que ve en aquellas "las represiones fundamentales de la verdad". ${ }^{44}$

Ellacuría vincula negativamente verdad con injusticia, en el sentido de que "la injusticia es la gran represora de la verdad"; pero, como él dice, se trata de una relación dialéctica, "ya que sólo en la lucha contra la injusticia $y$ en el retroceso de ésta se abrirá campo a la posibilidad real de la verdad". Por esta razón, ambas tareas -la lucha contra la injusticia y la búsqueda de la verdad- no pueden ni deben separarse y trabajarse de forma independiente.

Lo anterior es lo que justifica la necesidad de que la universidad, como buscadora de la verdad, "se dedique negativamente a la lucha por la desaparición de la injusticia $y$, positivamente, a la lucha en favor de la libertad", y a que se proponga, por tanto, cumplir su misión desde la perspectiva de la defensa de los derechos humanos de las mayorías populares oprimidas y de su liberación. ${ }^{45}$

Otra manera de justificar esto mismo, según Ellacuría, es aceptar que "la existencia de mayorías populares oprimidas representa, en sí misma, la negación existencial $y$ material más fuerte de la verdad $y$ de la razón", por lo que su superación 
"es uno de los desafíos mayores que se presentan a la inteligencia y a la voluntad de la universidad para que ellas encuentren la respuesta teórica adecuada y la solución práctica efectiva". ${ }^{46} \mathrm{O}$ para expresarlo de una manera más actual: ¿Por qué la universidad debe ocuparse primariamente de las víctimas de la sociedad, o de las víctimas de todo sisterna? La respuesta sería: porque es un hecho real, es un hecho irracional y es un hecho injusto, y la universidad por las exigencias de la realidad, de la razón, de la verdad y de la justicia, no puede sino asumir su superación como objetivo primario de su misión universitaria.

Ellacuría insiste en esto, porque está combatiendo la idea de que la universidad debe dedicarse primariamente a atender las necesidades del sector productivo y de la modernización de la sociedad, y secundariamente a ejercer una función social supletoria a favor de los sectores pobres. ${ }^{47}$ En este modelo, la universidad busca atender primariamente las necesidades de las empresas y de los productores en detrimento de su quehacer social y político y de la actividad humana. Según esto, a la universidad se va a aprender los saberes, las experiencias, las herramientas para el aprendizaje y los contenidos básicos. A la universidad le corresponde introducir a los alumnos en el mundo de la ciencia y de la tecnología, con todo lo que implica de modernización de las mentalidades y de sometimiento a la autoridad académica y a la dis- ciplina estricta del aprendizaje. ${ }^{48}$ Lo cual es cierto y válido, pero no es suficiente para el tipo de universidad que la UCA ha pretendido ser y pretende ser, en el contexto de la realidad histórica salvadoreña, centroamericana y latinoamericana.

Ellacuría denuncia la "trampa mortal" de este tipo universidad cuyo rol se reduce a dos tareas que se supone deben ser realizadas por ella y que tienen que ver con el desarrollo y el crecimiento económico: la formación de técnicos, $y$ en general de élites dirigentes, y la transmisión de determinados saberes técnicos, sin los cuales una sociedad no podría subsistir, una vez que ha entrado en el circulo del mercado capitalista. Se dice que la sociedad necesita la formación de élites dirigentes para afrontar las necesidades de las mayorías populares; "con lo cual dice Ellacuría - o se robustece más a los detentadores del poder económico, que racionalizan la explotación con la ayuda de élites dirigentes, muchas de ellas formadas en la universidad, o se crea una clase de tecnócratas, que busca su propia reafirmación y autoreproducción, que le permite ser una minoría y le permite separarse de los modos de vida de las mayorías populares". ${ }^{49}$ El segundo aspecto consiste en la recepción de unas técnicas y de un conjunto de saberes, valores y pautas de conducta, que se suponen son necesarios para el desarrollo y para una vida "feliz", "pero que, de hecho, son el cebo para perpetuar el sistema, en el cual siempre 
son favorecidos... no las mayorías populares, sino... los más fuertes, los que lograron inicialmente una mayor acumulación de capital y de recursos educativos". 50

En resumen, concluye Ellacuría sintetizando esta cuestión: "son necesarios los profesionales y los saberes técnicos para salir del subdesarrollo, pero esos mismos profesionales y saberes técnicos mantienen la marginación y el subdesarrollo de la inmensa mayor parte de la humanidad. Es evidente, como hecho, que en la historia del mundo nunca hubo tantos hombres (seres humanos) tan pobres, tan desposeídos, sobre todo en relación con tan po$\cos$ ricos $y$ depredadores". ${ }^{51}$

Entonces, la salida a la trampa mencionada está en que la universidad asuma conscientemente a las mayorías populares como su objetivo último e integral. Para Ellacuría, la liberación y la superación de las mayorías populares tienen en sí mismas características más que suficientes para potenciar e integrar cualesquiera objetivos legítimos, que pueda proponerse la universidad como un todo o en cada uno de sus sectores, ya sea en el ámbito de la docencia, de la investigación y de la proyección social, sin perder por ello rigor científico y calidad académica y técnica. ${ }^{52}$

La universidad debe jerarquizar sus actividades, según el criterio de las mayorías populares y de lo que más favorece la satisfacción de sus necesidades $y$, en definitiva, su liberación. Este principio permite jerarquizar "qué se debe investigar prioritariamente, qué se debe intentar enseñar y cómo, qué dimensión debe tener la universidad y cuántos alumnos deben ser aceptados, qué carreras deben tener prioridad y como deben ser estudiadas, qué valores y qué formación profesional deben ser impartidos, qué estructura debe tener la propia universidad". ${ }^{53}$

De lo que se trata, dice Ellacuría, no es crear una "universidad popular", en el sentido usual que se ha entendido, ni una universidad que dedique una parte sustancial de su esfuerzo a la extensión cultural, sino una universidad que se convierta en la "razón pública y procesada" de la razón de las mayorías populares, la cual "siendo verdadera razón, no puede presentarse como tal, porque no se ha posibilitado al pueblo articular su razón en razones y razonamientos". ${ }^{54}$

Consecuente con este planteamiento, Ellacuría afirma que la universidad debe convertirse en un "lugar de libertad", entendiendo por dicha libertad, no lo que comúnmente entendemos por ella, ya sea libertad de cátedra o autonomía universitaria, sino el esfuerzo que debe hacer la universidad en cuanto tal para liberarse, para separarse lo más crítica y radicalmente posible, de las exigencias del sistema y al cual de algún modo se ve obligada a servir (momento de liberación-de), con el fin de "volcarse al servicio liberador de las mayorías oprimidas" (momento de liberación-para). 
Es un esfuerzo de liberación que también debe realizar la comunidad universitaria: "si esta comunidad - dice Ellacuría - reproduce los intereses del sistema social imperante y de las minorías dominantes... si los estudiantes acuden al recinto universitario para lograr un puesto dominante y lucrativo en una sociedad injustamente estructurada, ya nos encontramos con una seria hipoteca de la labor universitaria ideal; si, lo que es peor, los profesores acuden a la univer- sidad con las mismas disposiciones e intereses con que otros profesionales acuden al mercado de trabajo, bien poco será lo que se pueda hacer. Si ni ellos ni la universidad como un todo están liberados de los préstamos que hace la sociedad para obligar a sus miembros a someterse a sus demandas, la batalla por ponerse a favor de las mayorías populares está perdida, por mucho que se utilicen lenguajes encendidos y demagógicos de liberación y de protesta" ${ }^{55}$

\section{Universidad y civilización del trabajo}

L

os planteamientos de Ellacuría en torno al papel político de la universidad se fueron ampliando $y$ profundizando, $y$ fueron adquiriendo cada vez más una perspectiva mundial. En su último discurso ${ }^{56}$, en noviembre de 1989 , con motivo de la concesión a la UCA del premio internacional Alfonso Comín, Ellacuría volvió a reiterar la tarea liberadora de la universidad y de los intelectuales, en general, en el marco de su crítica radical a la civilización del capital y de su propuesta alternativa de una civilización del trabajo o de la pobreza. En esos momentos, Ellacuría ya conocía las dificultades, las desviaciones y los fracasos de los procesos revolucionarios en América Latina, especialmente en Nicaragua, Guatemala y EI Salvador, de la perestroika en la ex Unión Soviética, de los graves problemas y de las lacras del llamado "socialismo real", y las dificultades que enfrentaban las fuerzas progresistas en esa época, en un contexto cultural cada vez más postmoderno y conservador. Sin embargo, él siguió sosteniendo la validez y la vigencia de sus ideas sobre la misión política de la universidad y del paradigma de la liberación.

En ese discurso, Ellacuría habló de la necesidad de promover un nuevo proyecto histórico y de "revertir el signo principal que configura la civilización mundial", desde la "perspectiva universal y solidaria de las mayorías populares". Para Ellacuría, la actual civilización del capital, ha ampliado la brecha de ricos y pobres, ha endurecido los procesos de explotación y de opresión con formas más sofisticadas, ha depredado ecológicamente la totalidad del planeta $y$ ha contribuido 
a la "deshumanización palpable de quienes prefieren abandonar la dura tarea de ir haciendo su ser con el agitado $y$ atosigante productivismo del tener, de la acumulación de la riqueza, del poder, del honor y de la más cambiante gama de bienes consumibles". ${ }^{57} \mathrm{El}$ "análisis coprohistórico" de las heces de nuestra civilización - afirmaba Ellacuría"parece mostrar que esta civilización está gravemente enferma". ${ }^{58}$

Los hechos actuales en el escenario nacional y mundial han venido a confirmar en lo fundamental este diagnóstico y a mostrar la necesidad, por tanto, de la exhortación de Ellacuría de "revertir la historia, subvertirla y lanzarla en otra dirección" ${ }^{\prime 59}$, con el fin de "evitar un desenlace fatídico y fatal" de la humanidad. El horizonte utópico de esta transformación debe ser la construcción de una civilización del trabajo como sustitutiva de la civilización del capital, en la que la primacía la tenga el trabajo humanizador frente al capital y sus dinamismos, que son los responsables del "mal común" predominante en la realidad histórica del presente y de la violación de los derechos humanos que hoy padece las mayorías de la humanidad, alojadas fundamentalmente en América Latina, Africa y Asia.

Un primer paso en esta transformación sería, según Ellacuría, "alimentar y provocar una conciencia colectiva de cambios sustanciales". Otro paso fundamental sería el de "crear modelos económicos, políticos y culturales" alternativos que hagan posible la transformaciones requeridas en la dirección del horizonte utópico propuesto. ${ }^{60}$

Es en este marco, afirmaba Ellacuría, donde la labor política de la universidad y de "los intelectuales de todo tipo, tienen un reto $y$ una tarea impostergables". No se trata de una tarea fácil, porque hay, decía Ellacuría, "una marea ideologizante" contraria a ella, que proclama la supuesta bondad y naturalidad de las Ilamadas "democracias liberales" occidentales y del capitalismo como alternalivas únicas y definitivas para la humanidad.61 De ahí la necesidad de desenmascarar esta "trampa ideológica" e ir construyendo modelos "que, en un fructífero intercambio de teoría $y$ praxis, den salida efectiva a ideales que no sean evasivos, sino animadores de una construcción histórica"62 liberadora.

"Nuestra contribución universitaria - concluía Ellacuría - pretende ante lodo contribuir a esta lucha histórica. Pensamos que debemos $y$, consecuentemente, queremos ser parte activa de esta lucha. Lo pretendemos ser universitariamente, pero eslo no significa primariamente, mediante la formación de profesionales, punto también importante, pero ambiguo, porque el país necesita un acelerado desarrollo económico, sino mediante la creación de un pensamiento, de modelos, de proyectos" que, partiendo de la negatividad de la situación y de la necesidad de superarla, "avance hacia soluciones, tanto coyunturales como estructurales, en todos 
los ámbitos de la realidad (histórica), tanto política, como religiosa, tanto económica como tecnológica, tanto artística como cultural. Esto requiere la mayor excelencia académica y sin ella poco contribuiríamos como intelectuales a problemas de tal complejidad; requiere también una gran honestidad, que no es solo vocación de objetividad, sino pretensión de máxima autonomía y libertad... Pero esto no bastaría si no tuviéramos claro dónde nos debemos situar como universitarios para encontrar la verdad histórica. Suele decirse que la universidad debe ser imparcial. Nosotros creemos que no. La universidad debe pretender ser libre y objetiva, pero la libertad y la objetividad pueden exigir ser parciales. Nosotros somos libremente parciales a favor de las mayorías populares, porque son injustamente oprimidas $y$ porque en ellas, negativa y positivamente, está la verdad de la realidad" ${ }^{63}$

Ellacuría no era dogmático en este tema de la universidad ni en otros, sobre todo por su insistencia - fundamentada filosóficamentede que la actividad intelectual debe siempre subordinarse a la realidad y a sus exigencias, tratando de superar cualquier esquema ideologizante. Lo importante es trabajar sobre la experiencia histórica de la universidad, para ir verificando ventajas $y$ desventajas de esta u otra dirección del trabajo universitario. "Una mezcla de teoría y praxis, en la que la praxis plantea las incógnitas y los desafíos y la teoría ofrece hipótesis de verificación junto con horizontes proyectivos, que han de ser comprobados o rechazados por una nueva praxis, puede ser el camino por donde avanzar hacia soluciones aceptables. Soluciones que, a su vez, han de ser revisadas por una teoría, que se comporte críticamente, de modo que se mantenga equilibrado y lúcido al vaivén más o menos dialéctico, según los casos, de la acción y el pensamiento"..$^{\text {st }}$

\section{Notas}

1 Discurso de la Universidad Centroamericana José Simeón Cañas en la firma del contrato con el BID, en UCA, Planteamiento universitario, San Salvador, 1989, pp. 9-10

2 Ibid.

3 Ibíd., p. 11.

4 Ibíd.

3 Ibíd., p. 12.

- R. Mayorga Quiroz, "La UCA hacia el futuron, en Planteamiento universitario, ob.cit., PP. 141-148.

, Ibid., p. 142.

- Ibíd. P. 143.

9 Ibíd.

Ibid., p. 144.

"IbId., p. 146.

12 I. Ellacurfa, "Diez años después, ies posible una universidad distinta?", 
Planteamiento universitario, ob.cit., Pp. 252-282.

Ibíd., p. 264. La liberación se refiere tanto a las estructuras como a las personas. El análisis científico de la realidad, por su mismo carácter, lleva a centrar la atención sobre males estructurales y reformas estructurales, pero el análisis filosófico ( $y$ el teológico) muestra que las dimensiones y las realidades personales son también momentos importantes de las estrueturas históricas, con una entidad propia y una relativa auto- nomía, y que, por tanto, no pueden soslayarse en la tarea histórica de liberación. Expresado de otra manera esto mismo: la universidad debe pretender la liberación y realización personal, pero esta no se logrará de forma realista si no se enmarca dicha liberación en la construcción de nuevas estructuras que exijan el comportamiento libre y pleno de las personas.

25 "Las funciones fundamentales de la universidad y su operativización", en Planteamiento universitario, ob.cit., Pp. 48-50.

26 Ibid., p. 51.

27 Ibíd.

28 Ibid., p. 56. Estrictamente, por proyección social, afirma Ellacurla, "debe entenderse lo que de la labor universitaria llega directamente a la sociedad; más en concreto, y supuesto el horizonte propio de esta universidad, lo que llega directamente a modo de "cultura" a las grandes mayorías oprimidas o, más en general, sobre lo que es acción directa de la universidad sobre la estructura social". En "Diez años después, ies posible una universidad distinta?" ob.cit., p. 277

$29 \quad$ Ibíd., p. 59. Desde su inspiración cristiana, la perspectiva formal con la que la universidad proyecta su labor liberadora, no es la del poder ni la de la dominación, sino la del servicio; ciertamente participa como universidad de un cierto poder, pero, dice Ellacuría, "es el poder de la esperanza, de la afirmación del futuro, de la lucha contra el mal". La universidad con inspiración cristiana no es o no debe ser el lugar de la seguridad, de los intereses egoístas, de lucros honoríficos o económicos, de ambi- 
ciones de poder y de dominio sobre los demás; es el lugar del sacrificio, de la entrega personal y de la renuncia.

Ibíd., P. 65.

I. Ellacuria, "Universidad y politica", Planteamiento universitario, ob.cit., Pp. 347-371.

32 En Escritos universitarios, UCA Editores, San Salvador, 1999, pp. 93-103.

33 Ibid., pp. 94-95.

Cf. Ibíd., p. 95

La UCA siempre ha tenido una visión estructural de la universidad y de sus funciones esenciales. Docencia, investigación y proyección social se codeterminan en su vinculación intrínseca, aunque en el comportamiento político de la universidad como un todo, la proyección social tenga la prioridad y marque la orientación y el contenido fundamental de las otras dos funciones.

36 Ibíd. La "extensión universitaria no debiera concebirse meramente como un llevar a la universidad hasta ciertos grupos que normalmente no accederían a ella, sino como un alcanzar directamente la conciencia colectiva de la nación", mediante el desenmascaramiento de la situación de las mayorías populares, la conciencia de sus derechos y de sus obligaciones en la construcción de una sociedad más justa. Cf. "Diez años después, ces posible una universidad distinta?", ob.cit., p. 278.

37 Ibíd., p. 360.

נ Cf. Ibíd., p. 361.

$39 \quad$ Ibíd., p. 367.

10 Escritos universitarios, UCA Editores, San Salvador, 1999, pp. 203-219.
1 "Universidad y política", ob.cit.

12 "Universidad, derechos humanos y mayorías populares", ob.cit., p. 203.

"Universidad y política", ob.cit., p. 366. En otro artículo, Ellacuría formula esta tesis así: en una sociedad dividida, "hay dos puntos de vista fundamentalmente opuestos: el de quien desde una situación de predominio ve en peligro sus ventajas y el de quien desde una situación de opresión ve la necesidad y el derecho que le asiste para salir de ella. Si se tipifica así la situación, es más probable que el sistema de razones, esgrimido por la parte oprimida, tenga mayor validez como conjunto; una validez ética y social, que si se acompaña de la debida reflexión crítica, estará más cerca de la objetividad social". En "La historización del concepto de propiedad como principio de desideologización" ECA, 335-336, 1976, p. 426

14 "Función liberadora de la filosolía", ECA, 435-436, 1985, p. 60.

15 "Universidad, derechos humanos y mayorías populares", ob.cit., pp.207208.

16 Ibíd., p. 208. En "Universidad y política", ob.cit., P. 355 , lo expresa así: "la injusticia lleva consigo una carga terrible de irracionalidad $y$, además, la irracionalidad es en nuestro caso un dato primario, ante el que una institución cultivadora de la razón no puede quedar imposibilitada. Aunque se considerara a la universidad como una institución social cuya finalidad última fuera introducir en el cuerpo social el máximo de racionalidad, dejando de lado coda intimación ética, la situación de nuestros países dominados y subdesarrollados exigiría su 
intervención precisamente por su radical situación de irracionalidad".

Cf. Miguel A. Escotet, Tendencias, Misiones y Políticas de la Universidad, UCA-Nicaragua-UNESCO, 1993, p.31.

4 Cf. Ximo García Roca, "Universidad y acción solidaria", Universidad de Valencia, 2001.

19 "Universidad, derechos humanos y mayorías populares", ob.cit., pp. 206-207.

so Ibíd., p. 207.

51 Ibíd.

52 Y esto por dos razones fundamentales. En primer lugar, porque la realidad histórica, para ser conocida, analizada, interpretada y valorada, exige una diversidad de disciplinas y técnicas, y una variedad y calidad de recursos intelectuales. "Es la realidad principio fundante $y$ determinante de la inteligencia y para nuestro caso es la realidad nacional, con su multiplicidad de aspectos y su entronque con la realidad universal histórica, el principio fundante y determinante de lo que debe ser el saber universitarion. Y en segundo lugar, por que la realidad (nacional, regional, global, la realidad histónica en definitiva), como objeto de estudio de la docencia y la investigación, "no puede percibirse de un modo integral y concreto más que desde ese elemento determinante que es el de las mayorías populares oprimidas, al menos en naciones subdesarrolladas como las nuestras". Ibíd., pp. 210-211

33 Ibíd., p. 212.

34 Ibíd., p. 215. Ellacurla aclara que la universidad no puede pretender sustituir las demandas empíricas de las mayorías en virtud de una presunta racionalidad, que conociera mejor las demandas reales de esas mayorías, a las que se impondría lo que debieran querer. No se trata de que la universidad se convierta en vanguardia ideológica de las mayorías, sino en una instancia que intenta reflexionar y procesar, desde un contacto directo con esas mayorías, lo que les llevaría mejor a la solución más racional de sus necesidades". Cf. "Universidad y política”, ob.cit., p. 369.

ss Ibíd., p. 217. Se debe lograr la constitución de una comunidad universitaria consciente de sus posibilidades reales y de sus obligaciones respecto de la sociedad, que sepa aunar dimensiones $\mathrm{y}$ potencialidades reales, actualmente desaprovechadas. Una comunidad compuesta por personas convencidas y comprometidas con las mayorías populares. Para Ellacuría, el camino universitario ofrece posibilidades excepcionales para servir a los demás. Ciertamente no es el camino del gobierno y del poder político o estatal, no es el camino de los partidos políticos sean de oposición o no lo sean, no es el camino de las organizaciones populares $y$ sindicales, no es el camino de la misión eclesiástica ni, por supuesto, es el camino de la empresa privada. El camino universitario es un cauce distinto, que tiene sus propias peculiaridades, que no necesita abandonar en su esfuerzo de participar en una praxis de liberación. Cf. “Diez años después, eses posible una universidad distinta?", ob.cic., p. 278.

56 "El desafío de las mayorías pobres", Escritos universitarios, ob.cit., pp. 296-306.

57 Ibid., p. 300. 
$58 \quad$ Ibid., pp. 301-302.

59 Ibíd., p. 301.

60 Ibíd., p. 302. Hasta ahora -reconocía Ellacuría en 1985-, la UCA ha hecho mejor la tarea del análisis y la denuncia que la tarea creativa de proponer marcos de solución y soluciones operativas. Se ha avanzado más por la negación de lo malo que por la proposición de lo bueno, "pero ya va siendo hora de que, sin abandonar el camino de la negación de lo negativo, construyamos desde lo negado soluciones positivas, que despierten esperanzas firmes y esfuerzos denodados". En "Los retos del país a la UCA en su vigésimo aniversario", Escritos universitarios, ob.cit., p. 265

${ }^{61}$ Cf. Ibíd.

62 Ibíd.

63 Ibíd., pp. 303-304

64 "Universidad y política", ob.cit., p. 348. 